\title{
BUILT ENVIRONMENT: RELATING THE BENEFITS OF RENEWABLE ENERGY TECHNOLOGIES
}

\author{
Abdeen Mustafa Omer \\ 17 Juniper Court, Forest Road West, Nottingham NG7 4EU, UK \\ Email: abdeenomer2@yahoo.co.uk
}

\begin{abstract}
Recently, environmental issues have been the focus of much of the world's attention. This has stimulated a response in many countries, which has led to a closer examination of energy conservation strategies for conventional fossil fuels. One way of reducing building energy consumption is to design buildings, which are more economical in their use of energy for: heating, lighting, cooling, ventilation and hot water supply. Passive measures, particularly natural or hybrid ventilation rather than air-conditioning, can dramatically reduce primary energy consumption. However, exploitation of renewable energy in buildings and agricultural greenhouses, can significantly contribute in reducing dependency on fossil fuels. Therefore, promoting innovative renewable applications and reinforcing the renewable energy market will contribute to preserving the ecosystem by reducing emissions at local and global levels. This will also contribute to the amelioration of environmental conditions, through a reduction in air pollution and greenhouse gases, by the replacement of conventional fuels with renewable energies.
\end{abstract}

Keywords: Built environment, energy efficiency, and environment impacts.

\section{INTRODUCTION}

Natural resources may be renewable, non-renewable or abstract. Non-renewable resources include fossil fuels, minerals, clear-felled tropical hardwoods, which are not replaced and rare animals or plants that are hunted or collected in an uncontrolled way. Renewable resources include energy from the sun and the biological and biogeochemical cycles (such as the water and energy hydrological and carbon cycle). At a more immediate level, renewable resources include forests that have been selectively felled and replanted, animal and plant populations that have been properly managed through controlled hunting, fishing and collecting and waters with controlled inputs that can be readily recycled and reused. Abstract resources include animals, plants and the natural landscape as part of 'the countryside', used for recreation and tourism activities, such as bird watching, fishing, hiking, sight-seeing, etc. Non-renewable resources are of course finite, while the other two categories are effectively infinite. Our descendants will not thank us for exhausting finite resources, nor for destroying the renewable ones.

In many countries, global warming considerations have led to efforts to reduce fossil energy use and to promote renewable energies in the building sector. Reductions in energy use can be achieved through minimising the energy demand, by rational energy use, by recovering heat and cold and by using energy from the ambient air and from the ground. To maintain the environmental impact of a building at sustainable levels (e.g., greenhouse gas neutral emissions), the residual energy demand must be covered by renewable energy. This thesis presents integral concepts for buildings with 
both excellent indoor environment control and sustainable environmental impact. Special emphasis is given to ventilation concepts utilising ambient energy from the air, ground and other renewable energy sources and on the interaction with heating and cooling. It is essential to avoid the need for mechanical cooling, e.g., through peak load cutting, load shifting and use of ambient heat or cold from the air or ground. Techniques considered are hybrid (controlled natural and mechanical) ventilation, including night ventilation, thermo-active building mass systems with free cooling in a cooling tower and air intake via ground heat exchangers. For both residential and office buildings, the electricity demand remains one of the crucial elements in meeting sustainability requirements. The electricity demand of ventilation systems is related to the overall demand of the building and the potential of photovoltaic systems and advanced cogeneration units.

The heating or cooling of a space to maintain thermal comfort is a highly energy intensive process, which accounts for as much as $60-70 \%$ of the total energy use in nonindustrial buildings. Of this, approximately $30-50 \%$ is lost through ventilation and air infiltration. However, the estimation of energy impact of ventilation relies on detailed knowledge about air change rate and the difference in enthalpy between the incoming and outgoing air streams. In practice, this is a difficult exercise to undertake, because there is much uncertainty about the value of these parameters (Martin, 2006). As a result, a suitable datum from which to develop strategic planning for improving the energy efficiency of ventilation has proved difficult to establish (Martin, 2006). Efforts to overcome these difficulties are progressing in the following two ways:

i) Identifying ventilation rates in a representative cross section of buildings.

ii) Establishing the energy impact of air change in both commercial and domestic buildings.

In addition to conditioning energy, the fan energy needed to provide mechanical ventilation, can make a significant additional contribution to the energy demand. Much depends on the efficiency of the design, both in relation to the performance of the fans themselves and to the resistance to flow arising from the associated ductwork.

The building sector is an important part of the energy picture. The major function of buildings is to provide an acceptable indoor environment, within which occupants are able to carry out various activities. Hence, the purpose behind this energy consumption is to provide a variety of building services, which include weather protection, storage, communications, thermal comfort, facilities of daily living, aesthetics and work environment, etc. However, the three main energy-related building services are space conditioning (for thermal comfort), lighting (for visual comfort) and ventilation (for indoor air quality). Pollution-free environments are a practical impossibility. Therefore, it is often useful to differentiate between unavoidable pollutants, over which little source control is possible and avoidable pollutants, for which control is possible. Unavoidable pollutants are primarily those emitted by metabolism and those arising from the essential activities of occupants. 'Whole building' ventilation usually provides an effective measure to deal with unavoidable emissions, whereas 'source control' is the preferred and sometimes only practical method to address avoidable pollutant sources (Limb, 2005). Hence, achieving optimum indoor air quality relies on an integrated approach to the removal and control of 
pollutants, using engineering judgment based on source control, filtration and ventilation. Regardless of the kind of building, good indoor air quality requires attention to both source control and ventilation. While there are sources common to many kinds of buildings, those focusing on renewable energy may have some unique sources and therefore, may require special attention (Erlich, 2010). In smaller (i.e., house size) buildings, renewable sources are already the primary mechanism for providing ventilation. Infiltration and natural ventilation are the predominant mechanisms for providing residential ventilation for these smaller buildings.

Ventilation is the building service most associated with controlling the indoor air quality, to provide a healthy and comfortable environment. In large buildings, mechanical systems normally supply the ventilation but in smaller ones, such as singlefamily homes, leakage through the building envelope is the principal supply, i.e., infiltration, which is a renewable resource, albeit unintentionally so. Ventilation can be defined as the process by which clean air is provided to a space, necessary to meet the metabolic requirements of occupants and to dilute and remove pollutants emitted within a space. Usually, ventilation air is conditioned by heating or cooling in order to maintain thermal comfort and hence, becomes an energy liability. Indeed, ventilation energy requirements can exceed 50\% of the conditioning load in some spaces (Erlich, 2010). Thus, excessive or uncontrolled ventilation can be a major contributor to energy costs and global pollution. Therefore, in terms of cost, energy and pollution, efficient ventilation is essential. Inadequate ventilation can cause comfort or health problems for the occupants. Good indoor air quality may be defined as air that is free of pollutants that cause irritation, discomfort or ill health to the occupants (Miller, 2000). Because a long time is spent inside buildings, considerable effort has focused on developing methods to achieve an optimum indoor environment. Achieving energy efficiency and optimum Indoor Air Quality (IAQ) depends on minimising the emission of avoidable pollutants. Pollutants inside buildings are derived from both indoor and outdoor contaminant sources.

\section{ENERGY-EFFICIENTCOMFORT}

In warm humid conditions, airflow can be an energy-efficient means to achieve indoor thermal comfort. Airflow does not create sensible cooling of air measurable by a thermometer; it conducts heat from our skin, which results in a cooling sensation (ASHRAE, 2005). This cooling sensation becomes noticeable with uniform airflow above $0.2 \mathrm{~m} / \mathrm{s}$. Airflow greater than $1.0 \mathrm{~m} / \mathrm{s}$ begins to disturb loose papers, which discourages utilisation of airflow greater than $1.0 \mathrm{~m} / \mathrm{s}$ in office-type spaces. Airflow up to $2.0 \mathrm{~m} / \mathrm{s}$ is frequently provided in industrial and storage buildings, as well as living areas and bedrooms in houses in hot humid climates. Many studies (ASHRAE, 2005) have modelled the cooling sensation of uniform airflow on human thermal response. In steady airflow, the cooling sensation $(C S)$ of airflow can be estimated in degrees Celsius using the equation:

$$
C S=3.67(V-0.2)-(V-0.2)^{2}{ }^{\circ} \mathrm{C}
$$

when average airflow, $V$, is in $\mathrm{m} / \mathrm{s}$. 
Natural ventilation from breezes or difference in air temperature generated by solar chimneys can induce passive indoor airflow. The problem with a passive approach is that breezes are not always present when needed and solar chimneys rarely produce enough airflow for comfort. Fans, particularly ceiling fans, can provide a reliable source for airflow for indoor thermal comfort in warm humid environments. Unsteady airflow with an appropriate gust frequency can enhance the cooling sensation. Airflow provides a cooling sensation for occupants of buildings in warm humid climates. The enhanced benefits of turbulent airflow with gust velocities within the range of $0.3 \mathrm{~Hz}$ to $0.5 \mathrm{~Hz}$ (with a peak preference at $0.47 \mathrm{~Hz}$ ), present further opportunities to utilise large, highvolume, low-speed ceiling fans for energy efficient cooling (Molla, 1997). This effect appears to be due to a peak response of human cold cutaneous thermoreceptors just beneath the skin.

As an alternative and new design philosophy, hybrid ventilation and cooling technologies (HVAC) combine the advantages of mechanical HVAC systems and natural ventilation. This has the potential to reduce energy consumption in many buildings, improve the occupants' comfort satisfaction level and minimise sick building syndrome (SBS). Hybrid ventilation and cooling provides opportunities for innovative solutions to the problems of energy-consuming environment control in buildings. Because hybrid systems combine natural and mechanical ventilation, they present several complex challenges to design and analysis tools, requiring a global approach that takes into account the outdoor environment, the indoor environment, control strategy and the mechanical system (Bahadori, 2008).

\section{BIOCLIMATIC DESIGN}

Bioclimatic design cannot continue as a side issue of a technical nature in main architectural design. In recent years, design has started to alter course and to become much more holistic in its approach to:

i) The achievement of a sustainable development.

ii) The depletion of non-renewable sources and materials.

iii) The life cycle analysis of buildings.

iv) The total polluting effects of buildings on the environment.

v) The reduction of energy consumption and

vi) Human health and comfort.

Hidden dimensions of architectural creation are vital to the notion of bioclimatic design. The most fundamental ones are:

TIME, which has been called the fourth dimension of architectural space, is of importance because every object cannot exist but in time. The notion of time gives life to an object and releases it to periodic (predictable) or spasmodic repetition. Time relates to seasonal and diurnal patterns and thus, to climate and the way that a building behaves or is designed in order to couple with and not antagonise nature. It further releases to the dynamic nature of a building in contrast to the static image that we have created for it. 
AIR is a second invisible but important element. We create space and pretend that it is empty, oblivious to the fact that it is both surrounded by and filled with air. Air in its turn, due to air-movement generated by either temperature or pressure differences, is very much there and alive. Building shapes, sections, heights, orientations and the size and positioning of openings should be related to the movement of air.

LIGHT and in particular daylight, is a third important element. Architecture cannot exist but with light and from the time we have been able to substitute natural light with artificial lighting, many buildings and a lot of architecture has become the poorer. It is not an exaggeration to say that the real form giver to architecture is not the architect himself but light and that the architect is merely the form moulder. Vernacular architecture is beautiful to look at as well as a significant on which to contemplate. It is particularly interesting to realise the nature of traditional architecture where various devices to attain thermal comfort without resorting to fossil fuels can be seen. Sun shading and cross ventilation are two major concerns in house design and a south-facing façade is mandatory to harness the maximum amount of sunshine in winter. Buildings built fifty years ago required high ceilings in order for natural ventilation to bring a cooling effect for the occupants. Modern high technology buildings have lower ceiling heights making air conditioning mandatory. In recognising the human right to enjoy modern life with a certain level of comfort and convenience, it is necessary to consider how people can live and work in an ideal environment with the least amount of energy consumption, in this age of global environment problems. People in the modern age could not tolerate such a poor indoor environment as people in the olden times used to endure. In those days people had to live with the least amount of fuel readily available and therefore, had to devise various means of constructing their houses so that they would be compatible with the local climate. Therefore, it is important in designing passive and low energy architecture for the future, to learn from their spirit in overcoming difficulties, by having their creative designs adapted to respective regional climatic conditions and try to devise eco-techniques in combination with a high grade of modern science.

\section{RELATIONSHIP BETWEEN CLIMATE, BIULDING AND OCCUPANTS}

In climate-sensitive architecture, strategies are adopted to meet occupants' needs, taking into account local solar radiation, temperature, wind and other climatic conditions. Different strategies are required for the various seasons. These strategies can themselves be subdivided into a certain number of concepts, which represent actions. The heating strategy includes four concepts (Figure 1):

i) Solar collection: collection of the Sun's heat through the building envelope.

ii) Heat storage: storage of heat in the mass of the walls and floors.

iii) Heat distribution: distribution of collected heat to the different spaces that require heating.

iv) Heat conservation: retention of heat within the building. 


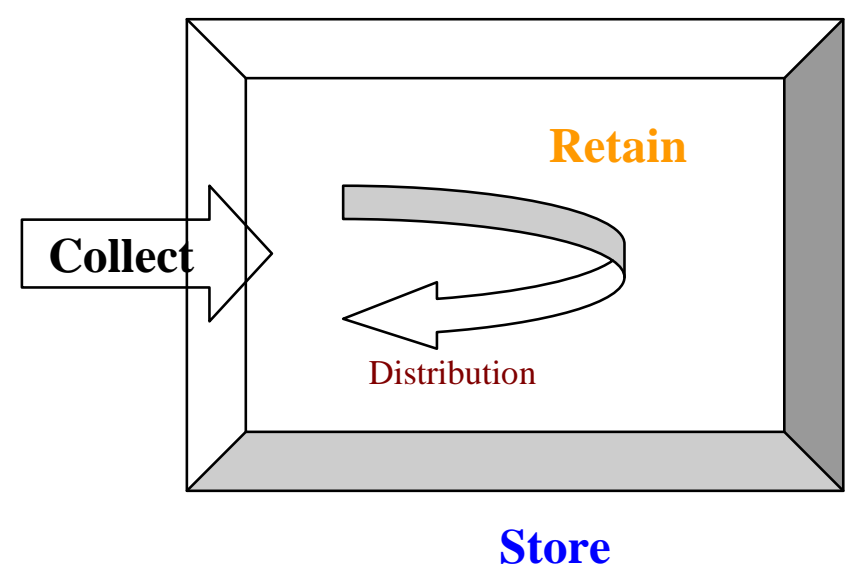

Figure 1. Heating strategy.

The cooling strategy includes five concepts (Figure 2):

i) Solar control: protection of the building from direct solar radiation.

ii) Ventilation: expelling and replacing unwanted hot air.

iii) Internal gains minimisation: reducing heat from occupants, equipment and artificial lighting.

iv) External gains avoidance: protection from unwanted heat by infiltration or conduction through the envelope (hot climates).

v) Natural cooling: improving natural ventilation by acting on the external air (hot climates).

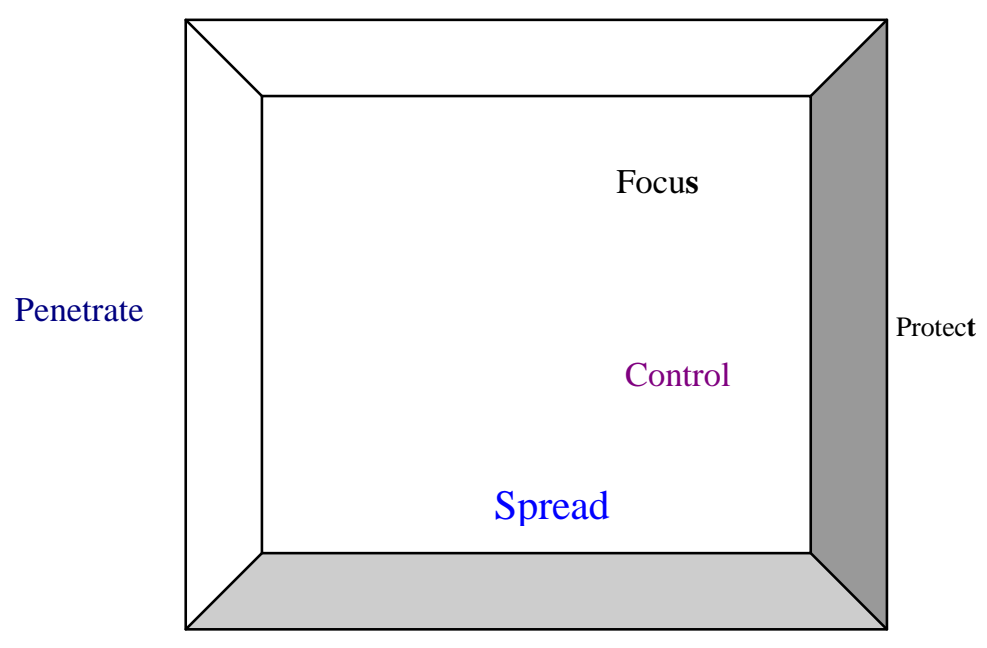

Figure 2. Cooling strategies.

The daylighting strategy includes four concepts (Figure 3):

i) Penetration: collection of natural light inside the building

ii) Distribution: homogeneous spreading of light into the spaces or focusing 
iii) Protect: reducing by external shading devices the penetration of Sun's rays into the building

iv) Control: control light penetration by movable screens to avoid discomfort

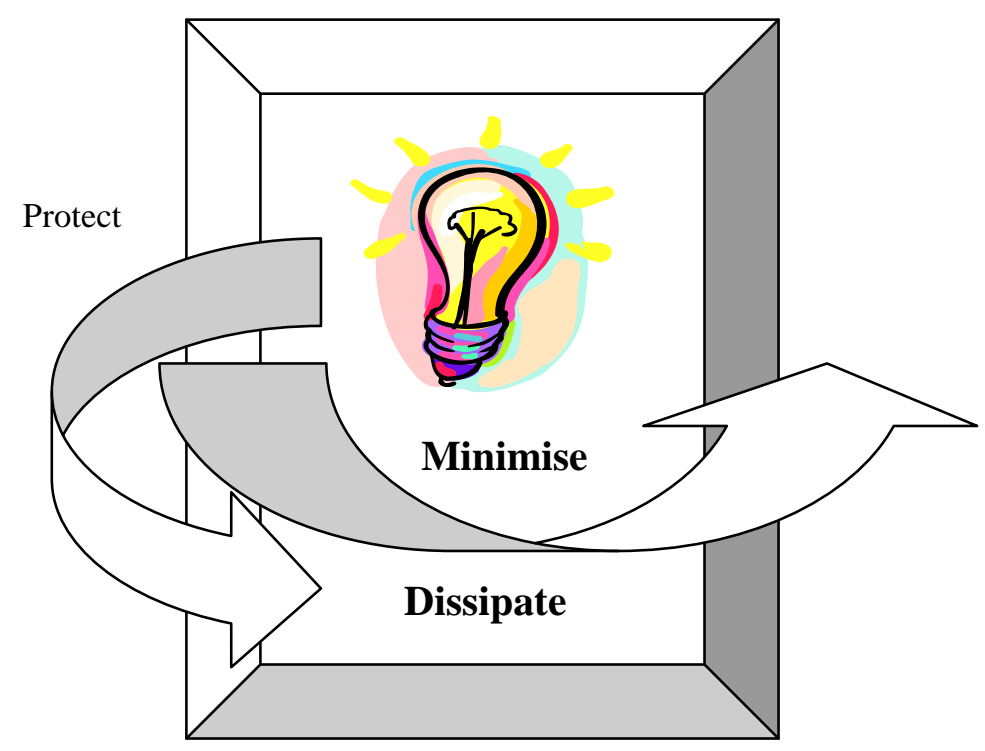

Figure 3. Daylighting strategies.

Buildings are important consumers of energy and thus, important contributors to emissions of greenhouse gases into the global atmosphere. The development and adoption of suitable renewable energy technologies has an important role. Ventilation is essential for securing a good indoor air quality but as explained earlier, can have a dominating influence on energy consumption in buildings.

Air quality problems are more likely to occur if air supply is restricted. Probably a ventilation rate averaging 7 1/s.p represents a minimum acceptable rate for normal odour and comfort requirements in office type buildings (Jonas and Patrik, 2009). Diminishing returns are likely to be experienced at rates significantly above $10 \mathrm{l} / \mathrm{s} . \mathrm{p}$ (Jonas and Patrik, 2009). If air quality problems persist, the cause is likely to be poor outdoor air quality (e.g., the entrainment of outdoor traffic fumes), poor air distribution or excessive release of avoidable pollutants into space. However, the energy efficiency of ventilation can be improved by introducing exhaust air heat recovery, ground preheating, demand controlled ventilation, displacement ventilation and passive cooling (Crisp et al., 2008). In each case, a very careful analysis is necessary to ensure that the anticipated savings are actually achievable. In addition, it is essential to differentiate between avoidable and unavoidable pollutant emissions. Achieving energy efficiency and optimum Indoor Air Quality (IAQ) depends on minimising the emission of avoidable pollutants. Pollutants inside buildings are derived from both indoor and outdoor contaminant sources. Each of these tends to impose different requirements on the control strategies needed to secure good health and comfort conditions. Integrating these strategies in climate-sensitive and energy-conscious architecture, is not only a way of saving money, it primarily provides the occupants with a more humane, valuable 
environment and ensures their well-being through the dynamic and harmonious interaction between man, building and climate.

\section{HEALTH AND THE BUILT ENVIRONMENT}

Two opposing trends threaten the engineers. The first is concern for global pollution where not only energy use but also energy sources are defined in terms of atmospheric contamination. The second is the demand for a performance specification for a more satisfying indoor climate. Thus, the engineers of today are facing two kinds of environmental forces:

i) The first is respect for the global external environment, which knows no natural boundaries and is now near saturation with pollution and may be affecting our climate in a harmful way. The second is a rising expectation of better indoor conditions, which in the past has meant a more energy intensive building through air conditioning. Safety issues and avoidance of exposure to toxic materials are increasingly becoming concerns for long-term health and welfare.

ii) The second trend is the continuing increase in energy use as the population rises and our productivity increases. Rising livings standards require more fuel to keep us cleaner and warmer and enable us to travel longer distances for recreation. More effective use of energy is now essential.

The four most important types of harm from man's activities are global warming gases, ozone destroying gases, gaseous pollutants and microbiological hazards (Table 1). The earth is some $30^{\circ} \mathrm{C}$ warmer due to the presence of gases but the global temperature is rising. This could lead to the sea level rising at the rate of $60 \mathrm{~mm}$ per decade with the growing risk of flooding in low-lying areas. At the United Nations Earth Summit in Rio in June 1992, some 153 countries agreed to pursue sustainable development (Horning and Skeffington, 2003). A main aim was to reduce emissions of carbon dioxide and other greenhouse gases. Reduction of energy use in buildings is a major role in achieving this. Carbon dioxide targets are proposed to encourage designers to look at low energy designs and energy sources.

Table 1. The external environment.

\begin{tabular}{lll}
\hline Damage & Manifestation & Design \\
\hline $\mathrm{NO}_{\mathrm{x}}, \mathrm{SO}_{\mathrm{x}}$ & Irritant & Low $\mathrm{NO}_{\mathrm{x}}$ burners \\
& Acid rain land damage & Low sulphur fuel \\
& Acid rain fish damage & Sulphur removal \\
& Global warming & Thermal insulation \\
$\mathrm{CO}_{2}$ & Rising sea level & Heat recovery \\
& Drought, storms & Heat pumps \\
$\mathrm{O}_{3}$ destruction & Increased ultra violet & No CFC's or HCFC's \\
& Skin cancer & Minimum air conditioning \\
& Crop damage & Refrigerant collection \\
Legionnellosis & Pontiac fever & Careful maintenance \\
& Legionnaires & Dry cooling towers \\
\hline
\end{tabular}


As our knowledge of satisfactory conditions develops, so we can control the physical environment to provide that satisfaction. Performance-based design will specify how many shall be satisfied. Target figures suggest satisfaction for $90 \%$ of the occupants is high quality, down to $70 \%$ for poor quality designs (Omer, 2009). Such performance values are being applied to a whole range of indoor factors such as air quality (Figure 4), thermal comfort, and noise levels.



Figure 4. Designing to a satisfaction level.

\section{ENERGY SAVINGS}

The admission of daylight to buildings alone does not guarantee that the design will be energy efficient in terms of lighting (Fanger, 2000; Fordham, 2000; Awbi, 2001). In fact, the design for increased daylight can often raise concerns relating to visual comfort (glare) and thermal comfort (increased solar gain in the summer and heat loss in the winter from larger apertures). Such issues will clearly need to be addressed in the design of the window openings, blinds, shading devices, heating systems, etc. Simple techniques can be implemented to increase the probability that lights are switched off (Givoni, 2006). These include: (i) making switches conspicuous, (ii) locating switches appropriately in relation to the lights, (iii) switching banks of lights independently and (iv) switching banks of lights parallel to the main window wall.

Large energy savings cover a wide range of issues including:

i) Guidelines on low energy design

ii) Natural and artificial lighting

iii) Solar gain and solar shading

iv) Fenestration design

v) Energy efficient plant and controls

vi) Examining the need for air conditioning

The strategy:

i) Integration of shading and daylighting: an integral strategy is essential and feasible where daylighting and shading can be improved simultaneously 
ii) Effect of shading on summer comfort conditions: solar shading plays a central role in reducing overheating risks and gives the potential for individual control but should be complimented with other passive design strategies

iii) Effect of devices on daylighting conditions: devices can be designed to provide shading whist improving the daylight conditions, notably glare and the distribution of light in a space, thus improving the visual quality

iv) Energy savings: energy savings from the avoidance of air conditioning can be very substantial, whilst daylighting strategies need to be integrated with artificial lighting systems to be beneficial in terms of energy use.

Thus, the energy potential of daylighting is inextricably linked with the energy use of the associated artificial lighting systems and their controls. The economics of daylighting are not only related to energy use but also to productivity. Good daylighting of workspaces helps to promote efficient, productive work and simultaneously increases the sense of well-being. However, energy and economics should not become the sole concern for daylighting design to the exclusion of perceptual considerations. The consultant in conservation and international recommendations (BSI 5454: 2007) established the following initial requirements for air quality in the archives:

i) Air temperature between $17^{\circ} \mathrm{C}$ and $19{ }^{\circ} \mathrm{C}$

ii) Relative humidity between $50 \%$ and $60 \%$ with lower values in the photographic archives

iii) Low levels of natural light and total exclusion of direct sunlight in archives, reading-rooms and complementary spaces

iv) Exclusion of ultra-violet radiation from natural and artificial lighting

v) Air filters to exclude particles larger than 0.01 microns (this requirement was relaxed, considering the high cost, additional energy requirements and problems of maintenance)

vi) Filters of active carbon to reduce the content of ozone, sulphur dioxide and oxides of nitrogen

The activities and operations of the occupants, their patterns of use and misuse, can have a significant effect on the energy performance of the intermediate and internal environments. The management and control of three interfaces: external to internal, external to intermediate and internal to intermediate, can also have a significant effect, particularly in response to seasonal, daily and hourly variations in solar energy availability, its regulation and distribution. Other facilities management functions can also have major energy implications, particularly maintenance, cleaning, replacement, refurbishment and adaptation. The benefits of passive solar environments include:

i) Reductions in non-renewable energy consumption and $\mathrm{CO}_{2}$ emission

ii) Savings in the cost of purchased energy generally

iii) Savings in space and water heating costs

iv) Amenity and social benefits to occupants

v) Prestige benefits to organisations

vi) Natural environment benefits for individual users

vii) Improved human comfort, well-being and performance. 
The potential risks that are commonly associated with passive solar environments include:

i) Increased purchased energy consumption through inappropriate use

ii) Seasonal overheating

iii) Unacceptable temperature fluctuations

iv) Poor air quality and condensation

v) Unacceptable lighting variation and glare

vi) Temperature stratification

vii) Thermal fatigue and fracture of materials

viii) Winter survival of plants

In practice, low energy environments are achieved through a combination of measures that include:

i) The application of environmental regulation and policy

ii) The application of environmental science and best practice

iii) Mathematical modelling and simulation

iv) Environmental design and engineering

v) Construction and commissioning

vi) Management and modifications of environments in use

The storage concept based on a modular design will facilitate active control and optimisation of thermal input/output and can be adapted for simultaneous heating and cooling, which is often needed in large service and institutional buildings. Such a system is illustrated in Figure 5; a conceptual integration of various warm/cold energy sources combined with thermal energy storage. Integrated energy systems need to be implemented at two levels:

i) Integration of various thermal energy sources into concurrent systems for heating, cooling and production of hot water.

ii) Physical integration of such systems into the building structure.

However, integrated energy systems for buildings face a number of barriers, of which the most significant are:

i) Lack of expertise, information and demonstration systems

ii) Immature products and service delivery chains

iii) Utilities that still favour central generation and the market power created by such infrastructure

iv) Electricity markets that do not yet account for environmental externalities

A building inevitably consumes materials and energy resources. The technology is available to use methods and materials that reduce the environmental impact, increase operating efficiency and increase the durability of buildings (Table 2). The objectives of sustainable building practices aim to:

i) Develop a comprehensive definition of sustainability that includes sociocultural, bio-climatic and technological aspects 
ii) Establish guidelines for future sustainable architecture

iii) Predict the $\mathrm{CO}_{2}$ emissions in buildings

iv) The proper architectural measure for sustainability is efficient energy use, waste control, population growth, carrying capacity and resource efficiency

v) Establish methods of design that conserve energy and natural resources

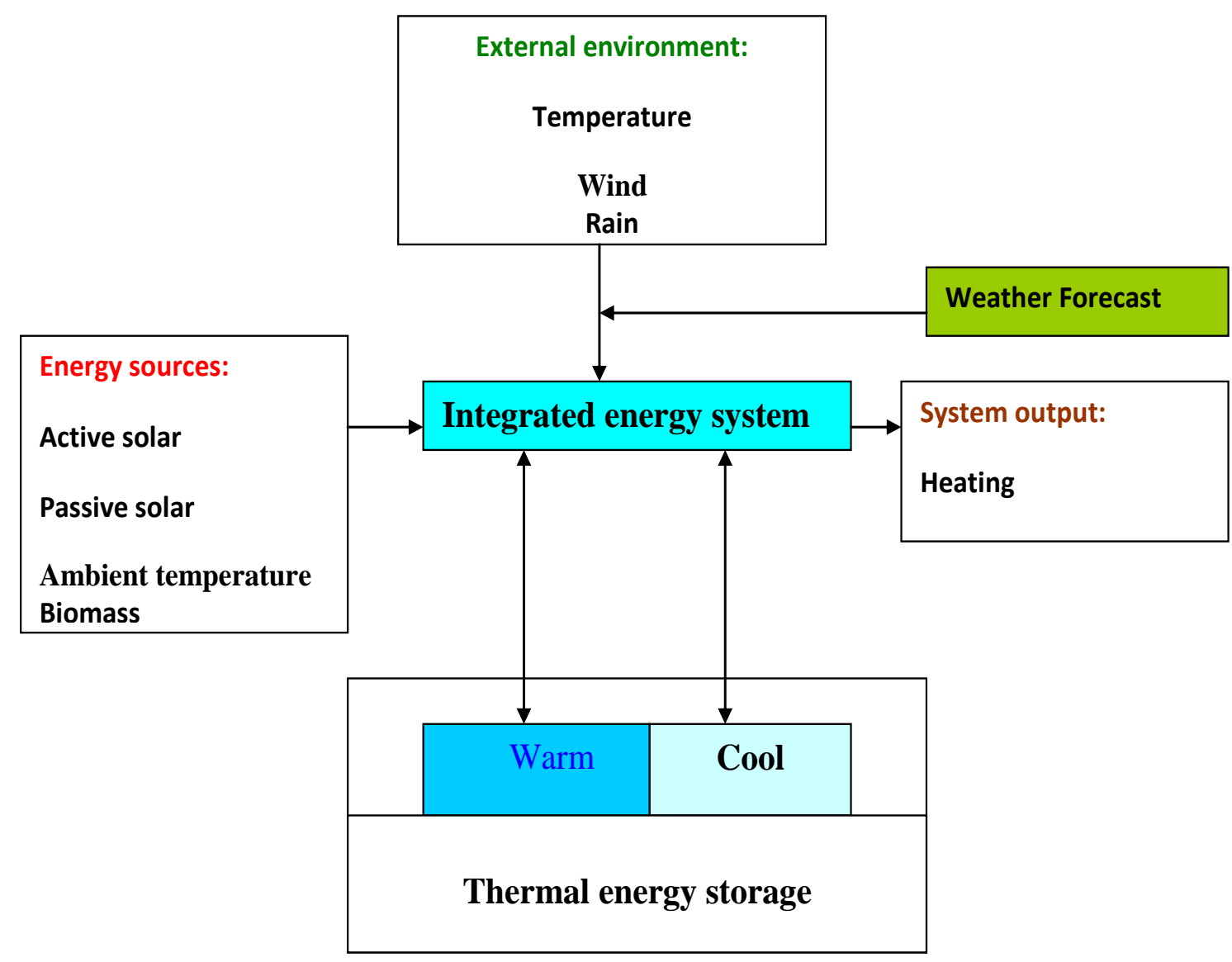

Figure 5. Conceptual illustration of an integrated energy system with thermal storage.

\section{RESULTS}

The move towards a low-carbon world, driven partly by climate science and partly by the business opportunities it offers, requires the promotion of environmentally friendly energy sources and alternatives, in order to achieve an acceptable stabilisation level of atmospheric carbon dioxide. This requires the harnessing and use of natural resources that produce no air pollution or greenhouse gases and provide a comfortable coexistence of humans, livestock and plants. Exploitation of renewable energy sources and particularly ground heat in buildings, can significantly contribute towards reducing dependency on fossil fuels and hence, achieving this goal. Due to the urgent need to mitigate greenhouse gas emissions, new and more efficient ways of utilising energy in space heating and cooling applications have been actively explored. Although fossil fuel installations and central air-conditioning systems constitute a dominant technology for the buildings sector, geothermal heat pumps establish an attractive alternative. 
Table 2. Design, construction and environmental control description of traditional and new houses.

\begin{tabular}{|c|c|c|}
\hline Design characteristics & Traditional houses & New houses \\
\hline Form & $\begin{array}{l}\text { Courtyard (height twice the } \\
\text { width)-open to sky }\end{array}$ & Rectangle-closed \\
\hline Construction & $\begin{array}{l}\text { Brick walls } 50 \mathrm{~cm} \text { thick, brick } \\
\text { roof with no insulation in } \\
\text { either }\end{array}$ & $\begin{array}{l}\text { Brick walls } 25 \mathrm{~cm} \text { thick, } \\
\text { concrete roof-no insulation }\end{array}$ \\
\hline Environmental control & Evaporative air coolers & Evaporative air coolers \\
\hline Ease of climatic control & $\begin{array}{l}\text { Difficult-rooms open into the } \\
\text { climatically uncontrolled open } \\
\text { courtyard }\end{array}$ & $\begin{array}{l}\text { Moderate-rooms open into } \\
\text { the enclosed internal } \\
\text { corridor }\end{array}$ \\
\hline Maintenance & $\begin{array}{l}\text { Well conserved and } \\
\text { maintained }\end{array}$ & New construction \\
\hline Windows & Vertical and single glazing & Horizontal-single glazing \\
\hline Urban morphology & $\begin{array}{l}\text { Each house attached from } 3 \\
\text { sides }\end{array}$ & $\begin{array}{l}\text { Row houses attached from } \\
2 \text { sides }\end{array}$ \\
\hline Orientation & $\begin{array}{l}\text { Varies-irregular shapes and } \\
\text { winding alleyways }\end{array}$ & North-south (row houses) \\
\hline $\begin{array}{l}\text { Orientation and solar } \\
\text { gain }\end{array}$ & $\begin{array}{l}\text { Solar gains less affected by } \\
\text { orientation due to shading } \\
\text { provided by the deep } \\
\text { courtyard }\end{array}$ & $\begin{array}{l}\text { Solar gain determined by } \\
\text { orientation-no obstruction } \\
\text { (shading) }\end{array}$ \\
\hline Sharing solar gain & $\begin{array}{l}\text { Significant - due to long-wave } \\
\text { exchange or convective } \\
\text { exchange between the } 4 \\
\text { vertical walls surrounding the } \\
\text { courtyard }\end{array}$ & $\begin{array}{l}\text { Minimal- S-wall receives } \\
\text { much more solar radiation } \\
\text { than the } \mathrm{N} \text {-wall due to the } \\
\text { absence of any inter- } \\
\text { reflection and long-wave } \\
\text { exchange }\end{array}$ \\
\hline Occupant's social status & Low income families & $\begin{array}{l}\text { Low and middle income } \\
\text { families }\end{array}$ \\
\hline
\end{tabular}

Utilised renewable resources currently account for about 9-10\% of the energy consumed in the world; most of this is from hydropower and traditional biomass sources (BS 5454. 2007). Wind, solar, biomass and geothermal technologies are already cost-effective in an increasing number of markets and are making important steps to broaden commercialisation. The present situation is best characterised as one of very rapid growth for wind and solar technologies and of significant promise for biomass and geothermal technologies. Each of the renewable energy technologies is in a different stage of research, development and commercialisation and all have differences in current and future expected costs, current industrial base, resource availability and potential impact on the energy supply chain. Recently, emphasis has been placed on the utilisation of ambient energy from ground source and other renewable energy sources, in order to stimulate the use of alternative energy sources for heating and cooling of buildings. Exploitation of renewable energy sources and particularly ground heat in buildings can significantly contribute towards reducing dependency on fossil fuels. 


\section{CONCLUSIONS}

There are clear benefits, which may accrue from the wider adoption of renewable energy technologies in building design. There are two key-elements to fulfilling the technological potential of renewable energy within the field of building design. Firstly, the appropriate skills and attitudes must be instilled in building design professionals and secondly, the provision of the opportunity for such people to demonstrate their skills. The higher education of building designers must include sustained development of attitudes and skills encompassing the use of renewable energy technologies. With environmental protection posing as the number one global problem, man has no choice but to reduce his energy consumption. One way to accomplish this is to resort to passive and low-energy systems to maintain thermal comfort in buildings. The conventional and modern designs of wind towers can successfully be used in hot, arid regions to maintain thermal comfort (with or without the use of ceiling fans) during all hours of the cooling season, or at least a fraction of it. Climatic design is one of the best approaches to reduce the energy cost in buildings. Proper design is the first step in defence against stress of the climate. Buildings should be designed according to the local climate in order to reduce the need of mechanical heating or cooling; hence, maximum natural energy can be used for creating a pleasant environment inside the built envelope. Technological and industrial progress of the last decade has spread electronic and informatics devices across many human activities and these now appear in building construction. The utilisation and operating opportunities of these components, increase the reduction of heat losses by varying the thermal insulation, optimising lighting distribution with louver screens and operating mechanical ventilation for coolness in indoor spaces. In addition to these parameters, the intelligent envelope can act for security control and became an important part of the building domotic revolution. Application of simple passive cooling measure is effective in reducing the cooling load of buildings in hot and humid climates. A reduction of $43 \%$ can be achieved using a combination of well-established technologies, such as glazing, shading, insulation and natural ventilation. More advanced passive cooling techniques, such as roof pond, dynamic insulation and evaporative water jacket need to be considered more closely. The building sector is a major worldwide consumer of both energy and materials and the consumption is increasing. Additionally, most industrialised countries are becoming more and more dependent on external supplies of conventional energy carriers i.e., fossil fuels. Energy for heating and cooling can be replaced by new renewable energy sources. However, new renewable energy sources are usually not economically feasible compared with the traditional carriers. In order to achieve the major changes necessary to alleviate the environmental impacts of the building sector, it is necessary to change and develop both the processes in the industry itself and to build a favourable framework to overcome the present economic, regulatory and institutional barriers.

\section{REFERENCES}

ASHRAE. 2005. Energy efficient design of new building except new low-rise residential buildings. BSRIASHRAE proposed standards 90-2P-1993, alternative GA. American Society of Heating, Refrigerating, and Air Conditioning Engineers Inc., USA.

Awbi, H. 2001. Ventilation of buildings. London: Spon. 
Bahadori, M.N. 2008. A passive cooling/heating system for hot arid regions. In: Proceedings of the American Solar Energy Society Conference. Cambridge. Massachusetts, pp. 364-367.

BS 5454. 2007. Storage and exhibition archive documents. London: British Standard Institute.

Crisp, V.H.C., Littlefair, P.J., Cooper, I. and McKennan, G. 2008. Daylighting as a passive solar energy option: an assessment of its potential in non-domestic buildings. Report BR129-BRE. Building Research Establishment, Garston. UK.

Erlich, P. 2010. Forward facing up to climate change, in global climate change and life on earth. R.C. Wyman (ed). London: Chapman and Hall.

Fanger, P.O. 2000. Thermal comfort: analysis and applications in environmental engineering. Denmark: Danish Technical Press.

Fordham, M. 2000. Natural ventilation. Renewable Energy, 19(1-2): 17-37.

Givoni B. 2006. Man climate and architecture. London: Applied Science Publisher Ltd.

Horning, M. and Skeffington, R. 2003. Critical loads: concept and applications. Institute of Terrestrial Ecology. London: HMSO.

Jonas, N. and Patrik, S.2009. Building and the environment. New York: NOVA Publishers.

Limb, M.J. 2005. Air intake positioning to avoid contamination of ventilation air: An annotated bibliography. UK: Air Infiltration and Ventilation Centre, University of Warwick Science park.

Martin, W. 2006. Air quality control in commercial buildings. WREC.

Miller, G. 2000. Resource conservation and management. California: Wadsworth.

Molla, M.S.A. 1997. Air pollutants and its probable transmutation in the ionosphere. Renewable Energy 10 (2-3): 327-329.

Omer, A.M. 2009. Energy efficiency, climate change, buildings and the need for development in renewable energy use, New York: NONA Publisher. 